\title{
BULLYING SOBRE JÓVENES LGTBI
}

\section{Analía Gómez Fernández}

Doctoranda del programa de doctorado Enfermería y Salud, Facultad de Medicina y Ciencias de la Salud, Campus de Bellvitge, Universitat de Barcelona, Barcelona, España. Matrona de Atención Primaria, Servicio Aragonés de Salud, Zaragoza, España.

Correo electrónico: analiagomez2@yahoo.es

Actualmente parece haber un incremento o quizás una mayor visibilidad de los casos de acoso escolar y violencia basada en no pertenecer a los patrones de género o sexualidad dominantes. Situaciones en las que se utiliza por tanto la identidad sexual para estigmatizar, etiquetar o menospreciar.

El bullying (en inglés), también conocido como acoso escolar o maltrato escolar, es cualquier forma de comportamiento violento a través de la cual un alumno o una alumna queda expuesto/a al aislamiento, exclusión, amenazas o agresiones físicas, psicológicas o sexuales por parte de sus iguales. Esta forma de violencia se reitera a lo largo de un tiempo determinado y se puede producir en el aula o a través de las redes sociales. Puede ser infringida por un agresor/a o un grupo, en general bajo el respaldo de los «colaboradores», puesto que el entorno de iguales suele ser testimonio y minimiza o ignora los hechos.

Las víctimas de bullying pertenecen a grupos minoritarios, socialmente estigmatizados, o se trata de personas con características individuales que el acosador o acosadora y su grupo perciben como indeseables. Desgraciadamente, en nuestra sociedad, la homofobia sigue siendo común, lo que implica que la juventud de lesbianas, gais, pero también transgénero, bisexuales e intersexuales (LGTBI) y las personas percibidas como LGTBI sean más vulnerables a sufrir bullying. Esto se hace extensible a los hijos e hijas 
de familias LGTBI o cualquier estudiante que muestre una expresión de género no normativa. Por ello, algunos autores prefieren utilizar el término más genérico de LGTBIfobia.

El bullying sobre jóvenes LGTBI se suele iniciar a edades muy tempranas, entre los 12 y los 15 años, manifestándose principalmente en forma de violencia psicológica. Esta discriminación, exclusión y violencia por motivos de orientación sexual e identidad de género suceden con frecuencia ante el silencio y/o el desconocimiento del profesorado y las propias familias. Solo una pequeña parte del alumnado que lo sufre se atreve a contarlo a algún adulto, la mayoría no lo hacen porque se avergüenza de ello o por miedo al rechazo. Tampoco suelen recibir apoyo por parte del grupo porque la estigmatización «se contagia» y viven por tanto este tipo de acoso en soledad. Soledad derivada en parte de la impunidad, puesto que muchas veces la violencia tiene lugar en los espacios públicos de las escuelas, por ejemplo, mediante insultos escritos en las pizarras, pero también impunidad porque, si por el contrario se denuncia, en muchos casos no se tiene en cuenta el componente de género de las agresiones.

La normalización de la LGTBIfobia provoca en las víctimas una interiorización negativa del autoconcepto, conduciendo a dolorosos sentimientos que generan desesperanza hacia el futuro. Pueden presentar, en consecuencia, trastornos emocionales, bajo rendimiento escolar y en caso extremos pueden llegar a atentar contra su propia vida con pensamientos suicidas o incluso llevando a cabo conductas autolesivas. Puede poner por lo tanto en peligro la vida de muchos jóvenes, al convertirse en una causa de riesgo de suicidio. Debería considerarse este tipo de violencia como un problema no solo de derechos humanos, social y de educación, sino también un problema de salud pública. 